\title{
Psoriasis in pregnancy: challenges and solutions
}

\author{
This article was published in the following Dove Press journal: \\ Psoriasis: Targets and Therapy \\ 18 May 2015 \\ Number of times this article has been viewed
}

\section{Gino Antonio Vena' \\ Nicoletta Cassano' \\ Gilberto Bellia ${ }^{2}$ \\ Delia Colombo ${ }^{2}$}

'Dermatology and Venereology Private Practice, Bari and Barletta, ${ }^{2}$ Novartis Farma SpA, Origgio, Varese, Italy
Correspondence: Gino Antonio Vena Dermatology and Venereology Private Practice, via Renato Coletta, 32, 76I2I Barletta, Italy

Email ginovena@gmail.com
Abstract: The available information about the effects of pregnancy on psoriasis and those of psoriasis on pregnancy is almost limited, despite the high frequency of the disease in the general population, as well as in women in reproductive years. Considering the existing evidence, pregnancy does not tend to have a negative influence on psoriasis, as in most women who experience a change in the severity and course of their psoriasis during pregnancy, the change is more likely to be reported as an improvement. This assumption can be applied more convincingly to plaque-type psoriasis, while an exception may be represented by generalized pustular psoriasis, which has been somehow linked to impetigo herpetiformis. Conflicting findings emerged from the few available studies that explored the effect of psoriasis on pregnancy outcomes. Recent studies found an association between moderate-to-severe psoriasis and some pregnancy complications, including pregnancy-induced hypertensive diseases, and have emphasized a trend toward a newborn with low birth weight in patients with psoriasis, especially in those suffering from severe forms. The safety profile during pregnancy is not completely known for many drugs used to treat psoriasis. Moisturizers and low- to moderate-potency topical steroids or ultraviolet B phototherapy represent the first-line therapy for pregnant patients. Many dermatologists may, however, recommend discontinuing all drugs during pregnancy, in consideration of medico-legal issues, and also taking into account that common forms of psoriasis do not compromise the maternal and fetal health. Anyway, for those women whose psoriasis improves during pregnancy, the interruption of any therapy for psoriasis can be a reasonable strategy. The objective of this paper was to review the most relevant literature data on psoriasis in pregnancy, trying to give concurrently practical information about clinical and prognostic aspects, as well as counseling and management.

Keywords: psoriasis, pregnancy, treatment, management, outcome, topical/systemic drugs, phototherapy

\section{Introduction}

The pathogenesis of psoriasis is thought to have an immune-mediated basis, with intricate interactions between a genetic background and several environmental triggering factors. A relevant immunopathogenetic role is played by Th1 and Th17 cells. ${ }^{1}$ Sex hormones may modulate the biological and immune responses in the skin, and can contribute to fluctuations in the activity of psoriasis during particular life periods of women (eg, menstruation, menopause, and pregnancy), also explaining some sex differences. ${ }^{2,3}$ Pregnancy is associated with pronounced endocrine changes, as well as substantial modulation of the immune response favoring a state of feto-maternal tolerance. ${ }^{4}$ While pregnancy was first recognized as a Th2 phenomenon, recent findings have shown an upregulation of several cytokines and cytokine-modulating molecules 
that can exert an anti-inflammatory effect in diseases with a prevailing Th1 response during pregnancy, in the absence of distinct predominance of a Th2 cytokine secretion pattern. ${ }^{4}$ Moreover, successful pregnancy outcome has been related to the activity of regulatory T-cells and decreased Th17 response, ${ }^{5}$ giving further hints for the understanding of pregnancy effects on autoimmune Th17-mediated disorders such as psoriasis.

The knowledge concerning the influence of pregnancy on psoriasis and that of psoriasis on pregnancy is scarce and derived from very few specific studies, despite the high frequency of the disease in the general population, as well as in women of childbearing age. Similarly, the safety profile during pregnancy is not completely known for many drugs used to treat psoriasis.

The objectives of this paper were to review the most relevant literature data on psoriasis in pregnancy, trying to provide concurrently practical information about clinical and prognostic aspects, as well as counseling and management.

\section{Influence of pregnancy on psoriasis}

The effects of pregnancy on autoimmune diseases are not univocal and seem to vary depending on the immunopathogenesis of such diseases. For instance, looking at the course of some rheumatic disorders during pregnancy, rheumatoid arthritis seems to have a beneficial effect, while ankylosing spondylitis and systemic lupus erythematosus show either no particular change or even an aggravation of symptoms. ${ }^{4}$

A retrospective study reviewed the data from 91 pregnancies of psoriatic women, showing improvement in $56 \%$ of cases, worsening in $26.4 \%$, and no variation in clinical course in $17.6 \%{ }^{6}$ Patients who improved in the first pregnancy reported a similar response in the following pregnancies. In one outpatient study, ${ }^{7}$ the affected body surface area (BSA) was assessed in 47 pregnant patients with psoriasis and in a control group of 27 nonpregnant, menstruating patients with psoriasis. Clinical evaluations were performed five times over a year. During pregnancy, $55 \%$ of patients reported improvement, $21 \%$ no change, and 23\% worsening of their psoriasis. Psoriatic BSA decreased significantly from 10 to 20 weeks' gestation. In the postpartum period, $65 \%$ of patients experienced worsening of their psoriasis, and $26 \%$ reported no change, whereas improvement was seen in only $9 \%$ of patients. A significant increase of BSA was registered by 6 weeks postpartum.

These results corroborated previous data obtained in a questionnaire-based survey conducted in 90 patients. ${ }^{8}$ A modification in the clinical course of psoriasis was observed during pregnancy by the majority of women (76.7\%), with improvement reported in most of them (63.3\% of the total). The amelioration of psoriasis was generally described as gradual, while those who experienced an abrupt improvement more commonly noted its occurrence in early phases of pregnancy. Moreover, a postpartum flare, linked to the sudden fall of estrogen and progesterone levels, was observed in $87.7 \%$ of patients, especially within 4 months of delivery.

In the light of some data, ${ }^{7}$ psoriasis improvement in pregnancy appeared to be correlated with high levels of estrogen in the absence of any apparent relation with progesterone levels alone. In contrast, other authors suggested this improvement to be associated with high concentrations of progesterone, which may downregulate T-cell response and have a direct effect on keratinocyte proliferation. ${ }^{8}$ Alternatively, the higher ratio of estrogen to progesterone would be relevant for immunoendocrine implications. ${ }^{9}$

Female carriers of HLA-Cw*0602 allele were found to experience substantial relief from psoriasis symptoms during pregnancy, whereas pregnancy-associated remission was described as rare in noncarriers. ${ }^{10}$

The available data seem therefore to indicate that pregnancy tends to have no detrimental influence on psoriasis severity and course, as, if there is a change during pregnancy, it is more likely to correspond to an amelioration rather than a worsening. This assumption can be applied more convincingly to plaque-type psoriasis. An exception can be instead represented by generalized pustular psoriasis, which has been somehow linked to impetigo herpetiformis (discussed separately). A retrospective study of 102 patients with adult-onset generalized pustular psoriasis recognized pregnancy as a trigger of the cutaneous disease in 17 cases. ${ }^{11}$ However, the development of the generalized pustular form in a pregnant woman may be considered an unpredictable event that should be managed cautiously because of potential complications. As specified later, impetigo herpetiformis can recur in subsequent pregnancies, and this aspect should be carefully discussed with the patient in consideration of future reproductive decisions.

\section{Pustular psoriasis of pregnancy}

Impetigo herpetiformis is a rare gestational dermatosis that displays clinical and histological features consistent with pustular psoriasis. For this reason, it is also known as generalized pustular psoriasis of pregnancy, although the exact nosology continues to be controversial, being still a matter of debate whether it should be considered a true variant of pustular psoriasis or a separate entity. ${ }^{12,13}$ Since the first description in 
1872 by von Hebra, who reported a high frequency of unfavorable maternal and fetal outcomes in his series of five affected pregnant women (with $100 \%$ fetal deaths and $80 \%$ maternal deaths), the literature later confirms the rarity of the disease and the potential risk of severe consequences for which immediate diagnosis and proper supportive treatment are mandatory. This approach has led to a better maternal prognosis, although the risk of stillbirth and perinatal mortality remains high, due to placental insufficiency, premature rupture of membranes, preterm labor, and fetal abnormalities. Collaboration between obstetricians, dermatologists, and neonatologists is often necessary to manage this disease, especially in refractory and severe cases requiring aggressive treatment modalities.

The disease has been regarded as a result of hormonal changes induced by pregnancy, although the exact mechanisms are still obscure. The pathogenic role of high progesterone levels was hypothesized, as well as the involvement of low levels of calcium or reduced skin-derived antileukoproteinase activity. ${ }^{13}$

Impetigo herpetiformis tends to develop during the last trimester of pregnancy and usually has a prompt resolution after delivery. Recurrences can be seen in subsequent pregnancies, sometimes with earlier onset and greater severity, or after the administration of oral contraceptives. Past or family history of psoriasis is generally but not constantly absent in the cases reported so far.

Clinically, impetigo herpetiformis is characterized by erythematous plaques surrounded by micropustules, often starting in flexural sites, that can become generalized. Constitutional disturbances may be present, including fever, chills, malaise, diarrhea, nausea, and arthralgia. Laboratory examinations may reveal leucocytosis with neutrophilia, elevated erythrocyte sedimentation rate, anemia, and hypoalbuminemia. Hypocalcemia has often been reported. ${ }^{12,13}$

Although the optimal strategies of therapeutic management have not yet been standardized, the treatment of choice is based on systemic corticosteroids. Replacement of calcium and correction of fluid and electrolyte imbalance should be instituted as needed. Although the pustules are sterile, some authors recommend adjuvant antibiotic treatment, especially in cases that responded poorly to systemic steroids, or when a secondary infection is suspected. ${ }^{14}$

Cyclosporine A (CsA) represents an alternative option in case of refractoriness to systemic corticosteroids, or as a steroid-sparing agent in order to taper off high dosages of steroids. The literature contains the reports of at least 14 cases of severe impetigo herpetiformis resistant to systemic corticosteroids treated with CsA, mostly in addition to corticosteroids, without relevant safety problems. ${ }^{15}$ In ten out of such cases, control of the disease was achieved.

\section{The impact of psoriasis on pregnancy outcomes}

The effect of psoriasis on pregnancy has been incompletely characterized. The few available studies dealt mainly with mild cases of plaque psoriasis and reported conflicting findings. Potential bias might result from the heterogeneous methodology of such studies or the source of information (eg, claims data), which can cause the risk of misclassification. ${ }^{16}$ Larger prospective studies are necessary to assess the impact caused on pregnancy outcomes by both the clinical severity of psoriasis and the drug therapy administered for psoriasis to pregnant women.

A cohort study of women suffering from psoriasis and other inflammatory skin diseases $(3,131$ pregnancies among 64,773 woman-years) disclosed little effect of skin diseases on the incidence or outcome of pregnancy. ${ }^{16}$ The risk of spontaneous abortion in the psoriasis group was similar to the risk in the control group. Another study analyzed the data set from the Danish National Birth Cohort, assessing 2,553 pregnancies in women with psoriasis, and found no increased risk of fetal death or prolonged time to pregnancy. ${ }^{17}$

Other studies detected a significant association between psoriasis and some pregnancy complications (Table 1). ${ }^{18-21}$ A key question was whether disease severity was more likely to be associated with increased risk of poor outcome, as described in the study of Cohen-Barak et al. ${ }^{19}$ These authors, in fact, found an association between moderate-to-severe psoriasis and some pregnancy complications (Table 1), including pregnancyinduced hypertensive diseases, such as gestational hypertension and preeclampsia, that are major causes of maternal and fetal morbidity and mortality. ${ }^{22}$ Women with hypertensive diseases of pregnancy may be more susceptible to future cardiovascular diseases, and psoriasis may share common risk factors. ${ }^{19}$

Adverse pregnancy outcomes in psoriatic women may also be conditioned by comorbidities or other health behaviors associated with psoriasis (ie, hypertension, obesity, dyslipidemia, psychiatric disorders, alcohol consumption, and smoking). A better understanding of the prevalence of potentially modifiable risk factors among women of reproductive potential with psoriasis can help improve birth outcomes.

Prospectively collected data from the Organization of Teratology Information Specialists (OTIS) Autoimmune Diseases in Pregnancy Project were examined to compare the prevalence of selected risk factors between 170 pregnant women with psoriasis and 158 nonpsoriatic women. ${ }^{23}$ 
Table I Most relevant studies that found an association of psoriasis with specific pregnancy outcomes

\begin{tabular}{|c|c|c|c|}
\hline Study & Study design and characteristics & Outcome significantly associated & Absence of association \\
\hline $\begin{array}{l}\text { Ben-David } \\
\text { et } \mathrm{al}^{18}\end{array}$ & $\begin{array}{l}\text { Single-center case-control study of I } 45 \\
\text { deliveries in } 84 \text { women with psoriasis during } \\
\text { I988-2004 (control group: } 860 \text { nonpsoriatic } \\
\text { women), using an obstetrics database }\end{array}$ & $\begin{array}{l}\text { Recurrent abortion (OR: } 2.1 \text { ) } \\
\text { Chronic hypertension (OR: 2.9) } \\
\text { Cesarean delivery (OR: } 4.1 \text { ) }\end{array}$ & Perinatal outcomes \\
\hline $\begin{array}{l}\text { Cohen-Barak } \\
\text { et a }{ }^{19}\end{array}$ & $\begin{array}{l}\text { Retrospective, matched cohort study of } 68 \\
\text { deliveries in } 35 \text { women with moderate-to- } \\
\text { severe psoriasis } \text { (control group: } 37 \text { deliveries in } 236 \text { nonpsoriatic women) }\end{array}$ & $\begin{array}{l}\text { Spontaneous (OR: } 5.6 \text { ) and induced } \\
\text { (OR: } 5.4 \text { ) abortions, newborn } \\
\text { macrosomia (OR: } 3.5) \text {, and premature } \\
\text { rupture of membranes (OR: } 3.5 \text { ) } \\
\text { Pregnancy-induced hypertensive } \\
\text { diseases ( } 7.4 \% \text { vs } 2.1 \% \text { ) }\end{array}$ & $\begin{array}{l}\text { Caesarean deliveries, recurrent } \\
\text { pregnancy losses, gestational or } \\
\text { pregestational diabetes, placental } \\
\text { complications or amniotic fluid } \\
\text { pathology, major fetal malformations } \\
\text { or newborn Apgar scores }\end{array}$ \\
\hline Yang et $\mathrm{al}^{20}$ & $\begin{array}{l}\text { Nationwide population-based study, using two } \\
\text { data sets, in I,463 mothers with a diagnosis } \\
\text { of psoriasis within } 2 \text { years before their index } \\
\text { deliveries, } 645 \text { in the severe psoriasis group } \\
\text { (control group: II,704 nonpsoriatic women) }\end{array}$ & $\begin{array}{l}\text { Newborn LBW for severe psoriasis } \\
\text { (OR: I.4) }\end{array}$ & $\begin{array}{l}\text { Preterm births, cesarean delivery, } \\
\text { preeclampsia or eclampsia (in all } \\
\text { patients) } \\
\text { LBW of infants (mild psoriasis) }\end{array}$ \\
\hline Lima et $\mathrm{al}^{21}$ & $\begin{array}{l}\text { Retrospective cohort study, at two tertiary } \\
\text { centers, of I62 pregnancies in I } 22 \text { women } \\
\text { with psoriasis (control group: } 50 \text { I pregnancies } \\
\text { in } 290 \text { nonpsoriatic women) }\end{array}$ & $\begin{array}{l}\text { Poor outcome composite (OR: I.89), } \\
\text { including preterm birth and LBW } \\
\text { Patients with psoriasis had a higher } \\
\text { proportion of each of the two outcomes } \\
\text { separately, but statistically significant } \\
\text { only when they were combined }\end{array}$ & $\begin{array}{l}\text { Cesarean delivery, preeclampsia/ } \\
\text { eclampsia, and spontaneous } \\
\text { abortion }\end{array}$ \\
\hline
\end{tabular}

Notes: ${ }^{a}$ Defined by the presence of documentation of past or current treatment with one or more of the following: phototherapy, methotrexate, cyclosporine, retinoids, and biological agents; 'befined on the basis of treatment with photochemotherapy or systemic therapy.

Abbreviations: LBW, low birth weight; OR, odds ratio.

Women with psoriasis were more likely to be overweight/obese prior to pregnancy, to smoke, or to have a diagnosis of depression, and less likely to take prenatal multivitamins or folic acid supplements in the periconceptional period.

Some studies have highlighted a trend toward a newborn with low birth weight in patients with psoriasis, especially in those suffering from severe forms. ${ }^{20,21}$ Other chronic immune-mediated disorders have been associated with pregnancy complications, including low birth weight and preterm birth, in correlation with disease activity. ${ }^{24,25}$ Of the mothers with severe psoriasis in the study of Yang et al, ${ }^{20}$ those who received systemic therapy during pregnancy did not have a higher risk of low birth weight, suggesting that this risk might be due to the disease itself. Cytokine imbalance can lead to endothelial dysfunction, resulting in systemic and placental vascular abnormalities. It has been postulated that placental vascular disease contributes to low birth weight, which is also a complication of preeclampsia. This last, in turn, is associated with inflammatory activity and an increase of the same cytokines as in psoriasis. ${ }^{26}$

\section{Management of pregnant women with psoriasis General aspects}

For those women whose psoriasis improves during pregnancy, the interruption of any therapy for psoriasis can be a reasonable strategy. Many dermatologists may recommend discontinuing all drugs during pregnancy, in consideration that common forms of psoriasis do not compromise the maternal and fetal health, and also taking into account medico-legal issues, which lead to an ever-growing trend toward cautious drug avoidance during this particular period. However, treatment discontinuation can be impractical for those with severe psoriasis. Anyway, teratogenic and other possible adverse risks for the child must be balanced with the risk from uncontrolled skin inflammation affecting the course of pregnancy and postpartum period.

Moisturizers and low- to moderate-potency topical steroids or ultraviolet (UV) B phototherapy represent the first-line therapy for pregnant patients. If moderate-to-severe psoriasis remains active or worsens during pregnancy, there might be a need for systemic treatment, and making the appropriate treatment decision can be difficult, primarily because of the general paucity of safety data for many medications during pregnancy. Some medications are known teratogens and mutagens and must be avoided. Others may be used in a relatively confident way. ${ }^{9}$ There are limited data in the literature regarding psoriasis, pregnancy, and systemic treatment. ${ }^{27}$ There are even less data from clinical trials, as pregnant women are traditionally excluded from these studies for ethical reasons. Knowledge derives from case reports and patient series describing the unintentional 
or deliberate drug exposure during pregnancies. Another source of information on the safe use of drugs in pregnancy was the US Food and Drug Administration (FDA) pregnancy categories system (Table 2, which also details the inclusion of the main treatments for psoriasis into risk categories). However, this categorization system showed obvious limits and imprecision, and the US FDA is implementing a new labeling rule designed to improve the assessment of the risk/ benefit ratio in pregnant and nursing mothers, trying to provide clear and exhaustive information for both patients and health care providers. ${ }^{28}$ The new rules abolish the distinction into five categories and take account of risk summary, clinical considerations, and data. The new labeling also reports information about pregnancy exposure registry for the drug,

Table 2 FDA pregnancy categories and inclusion of antipsoriasis drugs

\begin{tabular}{|c|c|}
\hline Type and description & Antipsoriasis drugs \\
\hline $\begin{array}{l}\text { Category A } \\
\text { Adequate and well-controlled studies have } \\
\text { failed to demonstrate a risk to the fetus in } \\
\text { the first trimester of pregnancy (and there } \\
\text { is no evidence of risk in later trimesters) }\end{array}$ & \\
\hline $\begin{array}{l}\text { Category B } \\
\text { Animal reproduction studies have failed to } \\
\text { demonstrate a risk to the fetus, and there } \\
\text { are no adequate and well-controlled studies } \\
\text { in pregnant women }\end{array}$ & $\begin{array}{l}\text { Systemic biologic drugs: } \\
\text { - Adalimumab } \\
\text { - Etanercept } \\
\text { - Infliximab } \\
\text { - Ustekinumab }\end{array}$ \\
\hline $\begin{array}{l}\text { Category C } \\
\text { Animal reproduction studies have shown } \\
\text { an adverse effect on the fetus, and there } \\
\text { are no adequate and well-controlled studies } \\
\text { in humans, but potential benefits may warrant } \\
\text { use of the drug in pregnant women despite } \\
\text { potential risks }\end{array}$ & $\begin{array}{l}\text { Topical drugs: } \\
\text { - Anthralin } \\
\text { - Calcipotriene } \\
\text { - Corticosteroids } \\
\text { Psoralens (PUVA) } \\
\text { Systemic drugs: } \\
\text { - Cyclosporine } \\
\text { - Corticosteroids }\end{array}$ \\
\hline $\begin{array}{l}\text { Category D } \\
\text { There is positive evidence of human fetal } \\
\text { risk based on adverse reaction data from } \\
\text { investigational or marketing experience } \\
\text { or studies in humans, but potential benefits } \\
\text { may warrant use of the drug in pregnant } \\
\text { women despite potential risks }\end{array}$ & \\
\hline $\begin{array}{l}\text { Category } \mathbf{X} \\
\text { Studies in animals or humans have } \\
\text { demonstrated fetal abnormalities, and/or } \\
\text { there is positive evidence of human fetal risk } \\
\text { based on adverse reaction data from } \\
\text { investigational or marketing experience; } \\
\text { the risks involved in use of the drug in pregnant } \\
\text { women clearly outweigh potential benefits }\end{array}$ & $\begin{array}{l}\text { Topical drugs: } \\
\text { - Tazarotene } \\
\text { Systemic drugs: } \\
\text { - Acitretin } \\
\text { - Methotrexate }\end{array}$ \\
\hline Category $\mathbf{N}$ & Topical drugs: \\
\hline FDA has not classified the drug & $\begin{array}{l}\text { - Coal tar } \\
\text { - Salicylic acid }\end{array}$ \\
\hline
\end{tabular}

Abbreviations: PUVA, psoralens and UVA; FDA, Food and Drug Administration. when available, and contains a subsection specially devoted to females and males of reproductive potential.

Animal studies can be useful in identifying the teratogenic potential of a drug, although the dosages used in animal models are many times greater than those used in clinical practice. ${ }^{29}$ Because of species differences, results from these studies cannot be generalized and directly applied to human beings.

Prospective registries remain the most important data source for understanding the effects of drugs during pregnancy. Unfortunately, the number of psoriatic patients included in the registries remains extremely low. ${ }^{27}$ This deficiency is even more remarkable if disease prevalence in general population is taken into account. Valuable data on the safety of systemic immunosuppressive drugs can be drawn from the larger population of patients with other autoimmune diseases and transplanted pregnant women. Although registries are important tools for identifying teratogenicity, they have limitations, such as the selection bias linked to voluntary reporting. Regulatory agencies have highlighted the importance of postmarketing safety surveillance for pregnant women and have encouraged the industry to address this pharmacovigilance issue. The OTIS Autoimmune Diseases in Pregnancy Study involves patients with psoriasis or psoriatic arthritis and is designed to evaluate the safety of specific medications taken for certain autoimmune conditions. ${ }^{27}$ A specific registry exists for patients with psoriasis and rheumatoid arthritis treated with CsA microemulsion, named Neoral Pregnancy Registry for Psoriasis and Rheumatoid Arthritis. ${ }^{30}$

A recent study sought to identify the medications most commonly prescribed in pregnant women with psoriasis using the Truven 2003-2007 MarketScan ${ }^{\mathrm{TM}}$ Medicaid Database (Truven Health Analytics, Ann Arbor, MI, USA). ${ }^{31}$ Among 560 pregnant women with psoriasis who met a physician before pregnancy, $68.9 \%$ filled psoriasis drugs. The most common medications prescribed were topical corticosteroids $(31.6 \%)$, with the majority being low to mid-potency $(64.8 \%)$. The second most common drug category (10.6\%) used was "other" topical products (including topical vitamin D analogs, topical calcineurin inhibitors, urea, salicylic acid, coal tar, and topical retinoid), followed by biologics $(0.5 \%)$ and other systemic treatments $(0.5 \%)$. Surprisingly, four patients (1\%) received either methotrexate or tazarotene during their pregnancy, known to be unsuitable and contraindicated during pregnancy.

\section{Topical therapy}

The use of topical agents for psoriasis during pregnancy can be viewed as controversial, although topical treatment is the 
recommended first-line treatment for psoriasis in pregnant patients. ${ }^{32}$ Moisturizers and emollients, such as petroleum jelly, should be tried initially, because these are known to be safe. Low- to moderate-potency topical corticosteroids should represent the next step, followed by high-potency topical corticosteroids, only if necessary, in the second and third trimesters. The safety of topical glucocorticoids varies with the strength of the agent and the specific vehicle employed. The current best evidence suggests that mild/moderate topical corticosteroids are preferred in pregnancy. The risks of high-potency topical steroids applied on large BSAs approach those observed with systemic steroids because of the increased potential for systemic absorption.

\section{Topical corticosteroids}

Percutaneous absorption of corticosteroids depends on numerous factors and is estimated to be $0.5 \%-7 \%$ in undamaged skin but can be greater in inflamed and/or damaged skin. ${ }^{26}$ Pregnancy, in turn, may alter the bioavailability of topical corticosteroids by modifying skin hydration and blood flow. The effect of corticosteroids on the fetus depends on transplacental passage, which is influenced by the activity of $11 \beta$-hydroxysteroid dehydrogenase (11 -HSDH), expressed in large quantities in the placenta and responsible for inactivation of cortisol. ${ }^{33}$ Metabolism of corticosteroids in the placenta is dependent on the specific molecule (as reported in the section related to systemic corticosteroids).
Fluticasone propionate and budesonide are not metabolized by $11 \beta-H S D H$, and would therefore be expected to reach the fetus in high concentrations.

According to a systematic review dated $2009,{ }^{34}$ limited and inconclusive data were unable to detect an association between topical corticosteroids and congenital abnormality, preterm delivery, or stillbirth. Although there was not any statistically significant difference between pregnant women who use and those who do not use topical corticosteroids, there did appear to be an association of very potent topical corticosteroids with low birth weight. Another concern is the risk of oral clefts, especially when used preconceptionally and in the first trimester of pregnancy, although there are still controversial findings. The results of the most important studies evaluating the effects of maternal topical corticosteroid exposure are summarized in Table $3 .{ }^{35-38}$

An evidence-based guideline on the use of topical corticosteroids in pregnancy stated that low- or moderatepotency corticosteroids are preferable to potent and very potent corticosteroids. ${ }^{39}$ The guideline recommended that the latter agents should be used as second-line treatment for very short periods and with appropriate obstetric monitoring (grade B evidence). The authors also postulated that lipophilic corticosteroids should theoretically produce fewer effects on the fetus (level D evidence), because they cause adverse effects less frequently and have the advantage of once-daily application. Moreover, pregnant women would be

Table 3 Main cohort studies exploring the effects of maternal exposure to topical corticosteroids

\begin{tabular}{|c|c|}
\hline Study characteristics & Summary of results \\
\hline $\begin{array}{l}\text { Population-based cohort study using the UK } \\
\text { General Practice Research Database } \\
(84,133 \text { pregnant women })^{35}\end{array}$ & $\begin{array}{l}\text { Significant association of fetal growth restriction with maternal exposure shortly before and } \\
\text { during pregnancy to high- and very-high-potency TCS (adjusted RR, 2.08), but not with mild/ } \\
\text { moderate TCS. } \\
\text { No associations of maternal exposure to TCS of any potency with orofacial cleft (cleft lip with } \\
\text { or without cleft palate, and cleft palate alone), preterm delivery, and fetal death (including } \\
\text { miscarriage and stillbirth). }\end{array}$ \\
\hline $\begin{array}{l}\text { Danish cohort study of all }(832,636) \text { live births } \\
\text { over a I2-year period }\end{array}$ & $\begin{array}{l}\text { No apparent association between any corticosteroid use and development of a cleft lip with or } \\
\text { without a cleft palate in the offspring. }\end{array}$ \\
\hline $\begin{array}{l}\text { Maternal first-trimester exposure to corticosteroids } \\
\text { in } 51,973 \text { pregnancies }(43.3 \% \text { exposed to TCS })^{36}\end{array}$ & $\begin{array}{l}\text { Increased risk of cleft lip with or without cleft palate associated with the use of TCS (OR: I.45), } \\
\text { but no increased risk with steroids in the form of inhalants, nasal sprays, and other topicals. } \\
\text { Exposure to oral corticosteroids during the first trimester in none of the infants with clefts. }\end{array}$ \\
\hline $\begin{array}{l}\text { Retrospective cohort study performed by the UK } \\
\text { National Health Service in } 2,658 \text { pregnant women } \\
\text { exposed to TCS and 7,246 unexposed pregnant } \\
\text { women }^{37}\end{array}$ & $\begin{array}{l}\text { No associations with orofacial cleft, low birth weight, preterm delivery, fetal death, low Apgar } \\
\text { score, and mode of delivery. Absence of any significant associations in most of these categories } \\
\text { by means of stratified analyses based on potency. } \\
\text { In an exploratory analysis, significantly increased risk of low birth weight when the dispensed } \\
\text { amount of potent or very potent TCS exceeded } 300 \mathrm{~g} \text { during the entire pregnancy (adjusted } \\
\text { RR, 7.74; } P=0.02 \text { ). }\end{array}$ \\
\hline $\begin{array}{l}\text { Norwegian report using two population-based } \\
\text { studies, and evaluating maternal first-trimester } \\
\text { exposure to corticosteroids (focusing on TCS) }\end{array}$ & $\begin{array}{l}\text { In the case-control study, association of TCS with both cleft lip with or without palate (adjusted } \\
\text { OR: } 2.3 \text { ) and cleft palate only (adjusted OR: } 3.4 \text { ). No evidence of this association in the cohort } \\
\text { data, although exposure to TCS was less specifically ascertained. No associations with other } \\
\text { types of corticosteroids. }\end{array}$ \\
\hline
\end{tabular}

Abbreviations: OR, odds ratio; RR, relative risk; TCS, topical corticosteroids. 
to advised not to apply large amounts over extensive areas or under occlusive dressings to avoid excessive absorption..$^{40}$ Topical corticosteroids can also increase the risk of developing stretch marks. ${ }^{41}$

\section{Other topical agents}

Based on the available data (Table 4), ${ }^{29,32,41-45}$ the use of anthralin, calcipotriene, coal tar, and topical salicylic acid is not recommended during pregnancy. ${ }^{32}$ When no alternatives exist, topical use of calcipotriene on small surfaces is permissible, ${ }^{41}$ and practical usage limits and avoidance of occlusive dressings can help avoid systemic absorption and lower the risk of toxicity. ${ }^{40}$

Despite the potential risks that have emerged from animal studies with coal tar, the literature on human exposure has failed to reveal any developmental effects. ${ }^{41}$ The results

Table 4 Relevant data on the safety in pregnancy of topical noncorticosteroid agents used for psoriasis

\begin{tabular}{|c|c|}
\hline Topical agent & Summary of data \\
\hline Anthralin & $\begin{array}{l}\text { No reproduction studies carried out in animals or in } \\
\text { human beings. }\end{array}$ \\
\hline Calcipotriene & $\begin{array}{l}\text { No studies performed on pregnancy in women. } \\
\text { In animal studies, increased incidence of skeletal } \\
\text { abnormalities, incomplete ossification of pelvic } \\
\text { bones and forelimb phalanges of fetuses. } \text {. }^{32,41}\end{array}$ \\
\hline Coal tar & $\begin{array}{l}\text { Possible risk of spontaneous abortion and congenital } \\
\text { malformations (limited number of cases). } \\
\text { In animal studies, association of maternal exposure } \\
\text { to high-dose coal products with perinatal mortality, } \\
\text { increased risk of cleft palates, and small lungs in } \\
\text { offspring. } \\
\text { Demonstration of the percutaneous absorption of } \\
\text { mutagens with measurable levels in the urine from } \\
\text { topically applied crude coal tar. }{ }^{42}\end{array}$ \\
\hline Salicylic acid & $\begin{array}{l}\text { No studies published on the use in pregnant women. } \\
\text { Absence of specific epidemiologic studies examining } \\
\text { the teratogenic effects. } \\
\text { In one case report, agnathia-otocephaly syndrome } \\
\text { linked to topical } 1 \% \text { salicylate. }{ }^{43} \\
\text { Topical absorption described as substantial and } \\
\text { variable, depending on the duration of contact and } \\
\text { the vehicle used. }{ }^{29} \\
\text { Association between maternal use of oral salicylates, } \\
\text { particularly aspirin, during the first trimester of } \\
\text { pregnancy and an increased risk of gastroschisis in } \\
\text { human infants. }{ }^{44}\end{array}$ \\
\hline Tazarotene & $\begin{array}{l}\text { In animal studies, increased rate of malformations } \\
\text { and fetal death in rats and rabbits treated with oral } \\
\text { tazarotene. }{ }^{32,41} \\
\text { In unpublished results of clinical trials, mention of } \\
\text { the birth of eight healthy children in six women } \\
\text { treated with topical tazarotene (without details on } \\
\text { doses or duration of treatment). }{ }^{45}\end{array}$ \\
\hline
\end{tabular}

of a retrospective study suggested that coal tar should be prohibited during the first trimester of pregnancy and, at the most, limited during the second and third trimesters. ${ }^{46}$

As with other retinoids, multiple animal studies have shown the teratogenic effects of tazarotene (Table 4). Unlike other topical retinoids, which were classified as pregnancy category $\mathrm{C}$, tazarotene has been classified as category $\mathrm{X}$. Considering that the bioavailability of tazarotene following topical application is $1 \%-5 \%$ in patients with psoriasis, the potential teratogenic effect should be much lower than that of oral retinoids. ${ }^{47}$

\section{Phototherapy}

Second-line treatment for pregnant women is narrowband UVB (NB-UVB) phototherapy or broadband UVB, if NBUVB is not available. The data for UVB phototherapy during pregnancy are limited. ${ }^{32}$ To date, however, it has not been associated with an increased risk of fetal abnormalities or premature delivery.

El-Saie et a ${ }^{48}$ found that high cumulative NB-UVB doses were able to induce folate photodegradation and decrease serum folate levels in patients with psoriasis and that this effect was related to the total cumulative NB-UVB dose. Another study showed that a standard course of NB-UVB, rather than prolonged treatment, did not have an effect on serum and red blood cell folate levels in psoriasis patients. ${ }^{49}$ To minimize the risk of low folate levels in pregnant women, some authors advise measuring serum folate levels before and throughout UVB treatment, and prescribing supplementation as needed. ${ }^{32}$

Despite the theoretical mutagenic and teratogenic effect of treatment with psoralens and UVA (PUVA), evidence seems to indicate that it apparently does not carry any significant risk for abnormal delivery outcome (Table 5), ${ }^{50,51}$ and this is consistent with the inclusion of PUVA into the pregnancy category C. ${ }^{51}$ Despite the reassuring results from a long-term prospective study (Table 5), the authors stressed that the power of the study was not strong enough to detect any specific adverse effect on pregnancy, and recommended to avoid PUVA treatment during pregnancy whenever possible because of the mutagenic properties.$^{50}$ It should be noted that phototherapy, as well as exposure to sunlight, may worsen melasma ${ }^{41}$ and patients should be counseled accordingly.

\section{Systemic traditional medications} Systemic corticosteroids (FDA category $\mathrm{C}$ ) are not routinely used in common forms of psoriasis, but they can be used in 
Table 5 Relevant data on the safety in pregnancy of PUVA therapy, systemic corticosteroids, and cyclosporine

\begin{tabular}{|c|c|}
\hline Treatment & Summary of data \\
\hline PUVA & $\begin{array}{l}\text { - Psoralens known as mutagens } \\
\text { - After } 12.8 \text { years of a prospective study, pregnancy outcomes were documented among women treated with PUVA ( } 93 \\
\text { women with } 159 \text { pregnancies). Exposure to PUVA at the time of conception or during pregnancy occurred in I9\%. There } \\
\text { was no evidence that PUVA affects the outcome of pregnancies or increases the risk of major malformations or stillbirth. }{ }^{50} \\
\text { - A study examined } 504 \text { and } 689 \text { infants born of pregnancies occurring after and before PUVA treatment, respectively, } \\
\text { whereas in another set of } 14 \text { cases, treatment occurred during pregnancy. After PUVA treatment, there was neither an } \\
\text { increased child mortality nor a higher frequency of congenital malformations. A marked increase in low-birth-weight infants } \\
\text { was observed when pregnancy occurred after treatment (effect attributed to the underlying disease). }{ }^{51}\end{array}$ \\
\hline $\begin{array}{l}\text { Systemic } \\
\text { corticosteroids }\end{array}$ & $\begin{array}{l}\text { - In a prospective study of } 184 \text { women exposed to prednisone in pregnancy, there was no statistical difference in the rate of } \\
\text { major anomalies compared to control groups. A meta-analysis showed a marginally increased risk of major malformations } \\
\text { after first-trimester exposure to corticosteroids and a } 3.4 \text {-fold risk of oral cleft. }{ }^{52} \\
\text { - An analysis of } 83,043 \text { primiparous women (I.7\% of whom used inhaled or oral corticosteroids from } 30 \text { days before } \\
\text { conception throughout the first trimester) showed no evidence of an association with the risk of congenital malformations in } \\
\text { progeny. }{ }^{53} \\
\text { - A previous report from the National Birth Defect Prevention Study (NBDPS), using data from } 1997 \text { to } 2002 \text {, found an } \\
\text { association with cleft lip and palate, but not cleft palate only. In contrast to previous results, a new analysis performed using } \\
\text { the NBDPS data from } 2003 \text { to } 2009 \text { (with a study population more than doubled in size) showed no association between } \\
\text { maternal corticosteroid use and cleft lip and palate in the offspring. }{ }^{54}\end{array}$ \\
\hline $\begin{array}{l}\text { Cyclosporine } \\
(\mathrm{CsA})\end{array}$ & $\begin{array}{l}\text { - In a retrospective study of } 629 \text { pregnant transplanted women exposed to CsA at doses of I.4-I4 mg/kg/d from week } 6 \\
\text { throughout pregnancy, no significant differences were observed with the general population in terms of the frequency of fetal } \\
\text { death or congenital malformations. There was, however, an increased rate of premature birth (44.5\%) and low birth weight } \\
(44.3 \%) \text { in the group of exposed women. }{ }^{55} \\
\text { - An analysis of } 15 \text { studies on the use of CsA in pregnant transplant recipients reported an increased rate of premature birth. } \\
\text { - An increase in birth defects was not detected among } 392 \text { pregnant transplant recipients treated with CsA (unknown dose } \\
\text { and duration of treatment). }{ }^{57}\end{array}$ \\
\hline
\end{tabular}

Abbreviations: PUVA, psoralens and UVA; CsA, Cyclosporine A.

selected cases or in patients with concomitant arthritis, and are considered a treatment of choice for impetigo herpetiformis. Table 5 contains the most relevant findings on the safety in pregnancy of systemic corticosteroids, along with PUVA therapy and CsA. ${ }^{50-57}$

There is conflicting evidence regarding the association of corticosteroid use in pregnancy and congenital malformations in offspring. ${ }^{52-54}$ According to some studies, ${ }^{53}$ the use of corticosteroids in early pregnancy was associated with congenital malformations, with relative estimates (odds ratio) from 0.8 to 2.1. Many previous epidemiologic studies, though not all, have reported increased risks of orofacial clefts after the use of oral corticosteroids, especially during the first trimester. ${ }^{32,41}$ For oral clefts, the odds ratio ranged from 0.6 to $5.2 .{ }^{53}$ Therefore, some authors stated that the use of systemic steroids in first trimester should be avoided. ${ }^{52}$ However, many of the previous studies were limited by a lack of statistical power, and some utilized postnatal interviews, with potential recall bias. Very recent data do not seem to confirm such an association. ${ }^{53,54}$

The effect of corticosteroids on the fetus will depend on transplacental passage, which is influenced by the activity of $11 \beta-H S D H$. Various authors have concluded that prednisone and prednisolone pose a very small risk to the fetus, as their metabolism by the placenta is higher than that of other formulations. ${ }^{41,58}$ Prolonged use of corticosteroids increases the risk of preterm delivery, intrauterine growth restriction, premature membrane rupture, and the frequency of maternal side effects such as hypertension, preeclampsia, eclampsia, gestational diabetes mellitus, and osteoporosis. Therefore, many clinicians recommend prolonged use of prednisone limited to $7.5 \mathrm{mg} / \mathrm{d}$ and the avoidance of more than $20 \mathrm{mg} / \mathrm{d}^{41}$

Cyclosporine passively crosses the placental blood barrier to achieve $10 \%-50 \%$ of the maternal plasma concentration. It has no mutagenic properties and is not teratogenic in animals or humans. CsA is not absolutely contraindicated in pregnancy and has been used successfully in pregnant women. Among the oral medications approved for psoriasis, CsA is considered the safest during pregnancy and has been suggested as a possible rescue therapy in severe refractory cases after thorough risk/benefit analysis. ${ }^{30,59}$ Experience from pregnant patients with autoimmune disease (including severe psoriasis and especially generalized pustular forms) is limited to case reports and case series, while the majority of information on CsA use during pregnancy derives from 
registries of transplant recipients, who usually receive higher doses than psoriasis patients. Thus far, most of the studies of pregnancies exposed to CsA have found an increase in premature delivery and low birth weight, but no increase in congenital malformations (Table 5). ${ }^{55-57}$ Whether premature delivery and low birth weight actually are side effects of CsA or are related to the underlying disease, comorbidities, or multidrug therapy is not clear. Moreover, no special pattern of birth defect or malformations were noted. There has been no clinical evidence of immunosuppression, increased infections, or nephrotoxicity in infants of mothers receiving CsA during pregnancy, although follow-up in the offspring is, to date, insufficient. ${ }^{30}$ No impairment in fertility was demonstrated in animal studies, as well as in human beings, including male transplanted patients. ${ }^{60}$

Methotrexate is absolutely contraindicated in pregnancy, as it is known to be an abortifacient, as well as a mutagenic and teratogenic agent. ${ }^{29}$ Men as well as women should be counseled to use effective contraception while being treated with methotrexate. It is recommended to interrupt the drug for at least 3 months before conception for both men and women.

Acitretin was initially introduced to replace etretinate due to its shorter half-life and more rapid elimination from the body. However, early reports highlighted the risk of metabolic formation of etretinate in acitretin-treated patients, especially by concomitant intake of ethanol, ${ }^{61,62}$ and raised doubts regarding the recommended length of anticonceptive period in women of childbearing age. Acitretin is contraindicated in human pregnancy, as well as in women who desire to have children or who cannot guarantee an effective contraception. Pregnancy should be avoided during treatment and up to 2 years after the end of therapy (up to 3 years, according to the US treatment guidelines), ${ }^{29}$ which makes acitretin an impractical and unsuitable therapy for women in their reproductive years.

Table 6 summarizes the information concerning the reproductive safety risk and teratogenic aspects of both methotrexate and acitretin. ${ }^{63-70}$

\section{Biologic therapy}

Etanercept, infliximab, adalimumab, and ustekinumab are the biological agents currently indicated for psoriasis (Table 7). Monoclonal antibodies are actively transported through the placenta, reaching high levels in blood in the newborn after being exposed in the late second and third trimester. The half-life of immunoglobulins in an infant is considerably longer than in adults. ${ }^{71}$ Both infliximab and adalimumab have been found in newborns in much higher concentrations than in their mothers' peripheral blood, and they remain detectable from 2 to 7 months after birth. Etanercept shows considerably less transplacental passage than the monoclonal antibodies. ${ }^{72}$ There is no published human study on ustekinumab so far; however, in an animal study on cynomolgus macaques, ustekinumab was detected in fetal serum as well as in the serum of infants as long as 120 days postpartum. ${ }^{73}$

According to current manufacturers' recommendations, all biologic agents are not recommended in pregnancy and should be discontinued for variable periods of time prior to conception, depending on elimination half-life and the duration of the biologic activity of these drugs (Table 7).

Table 6 Methotrexate and acitretin: reproductive safety risk and teratogenesis

\begin{tabular}{|c|c|}
\hline Medication & Most relevant findings \\
\hline Methotrexate & $\begin{array}{l}\text { - Abortifacient, mutagenic and teratogenic agent in animals and humans; considered a potent teratogen when used in high doses for } \\
\text { cancer or termination of tubal pregnancy. } \\
\text { - The sensitive period for the production of malformations is } 6-8 \text { weeks after conception for doses greater than I0 mg/wk. } \\
\text { - Prenatal exposure in the first trimester increases the risk of hydrocephalus, anencephaly, cranial dysostosis, cerebral anomalies, } \\
\text { dysmorphic facies, skeletal malformations, and limb defects. }{ }^{63} \text { In later stages of pregnancy, there is an association with growth } \\
\text { retardation and functional abnormalities. } \\
\text { - Doses higher that } 10 \mathrm{mg} / \text { wk increase the risk of embryopathy, including pulmonary atresia, congenital cardiopathy, abnormalities } \\
\text { of the skull and face (eg, craniosynostosis), failure of ossification, and limb defects. }{ }^{64} \\
\text { - The risk of malformations has been perceived as relatively low at the low weekly doses used for psoriasis and rheumatological } \\
\text { disorders. }{ }^{65} \text { However, typical embryopathy has also been described with low once-weekly dose schedule. }{ }^{66} \\
\text { - It is thought to affect spermatogenesis, inducing chromosomal alterations or single-gene mutations, and impairing sperm } \\
\text { mobility. }{ }^{67}\end{array}$ \\
\hline Acitretin & $\begin{array}{l}\text { - Administered in the first trimester of pregnancy, it increases the risk of spontaneous abortion and congenital defects, such as } \\
\text { craniofacial and ear anomalies, central nervous system, limb, thymic, and cardiovascular malformations ("retinoid embryopathy"). }{ }^{68} \\
\text { - Males treated with retinoids have no reproductive safety risk. } .^{67,69} \\
\text { - Inadvertent exposure to acitretin-contaminated blood products was recently found to be without adverse pregnancy outcomes, } \\
\text { probably because of the removal of acitretin and etretinate during the manufacturing process of blood products. }{ }^{70}\end{array}$ \\
\hline
\end{tabular}


Table 7 Characteristics of biologic drugs approved for psoriasis and safety data in pregnancy

\begin{tabular}{|c|c|c|c|c|}
\hline & Adalimumab & Etanercept & Infliximab & Ustekinumab \\
\hline Structure & $\begin{array}{l}\text { IgGI monoclonal antibody } \\
\text { targeting TNF- } \alpha\end{array}$ & $\begin{array}{l}\text { Fusion dimeric protein } \\
\text { containing the Fc domain } \\
\text { of human IgGI and TNF } \\
\text { receptor-2 (TNFR2/p75) }\end{array}$ & $\begin{array}{l}\text { IgGI monoclonal antibody } \\
\text { targeting TNF- } \alpha\end{array}$ & $\begin{array}{l}\text { IgGI monoclonal } \\
\text { antibody binding to the } \\
\text { P40 subunit of IL-I } 2 \\
\text { and IL-23 }\end{array}$ \\
\hline $\begin{array}{l}\text { Contraception } \\
\text { in women of } \\
\text { childbearing potential }\end{array}$ & $\begin{array}{l}\text { During therapy and for at least } \\
5 \text { months after therapy }\end{array}$ & $\begin{array}{l}\text { During therapy and for } \\
3 \text { weeks after therapy }\end{array}$ & $\begin{array}{l}\text { During therapy and for at least } \\
6 \text { months after therapy }\end{array}$ & $\begin{array}{l}\text { During therapy and for } \\
\text { at least I } 5 \text { weeks after } \\
\text { therapy }\end{array}$ \\
\hline Pregnancy & $\begin{array}{l}\text { Limited clinical data on exposed } \\
\text { pregnancies. Preclinical data on } \\
\text { postnatal toxicity not available } \\
\text { In a developmental toxicity } \\
\text { study in monkeys, no indication } \\
\text { of embryotoxicity, maternal } \\
\text { toxicity, or teratogenicity } \\
\text { Not recommended during } \\
\text { pregnancy }\end{array}$ & $\begin{array}{l}\text { In developmental toxicity } \\
\text { studies performed in rats } \\
\text { and rabbits, no evidence } \\
\text { of harm to the fetus or } \\
\text { neonatal rat } \\
\text { No studies in pregnant } \\
\text { women } \\
\text { Not recommended during } \\
\text { pregnancy }\end{array}$ & $\begin{array}{l}\text { The moderate number (nearly } \\
450 \text { with } 230 \text { during the first } \\
\text { trimester) of prospectively collected } \\
\text { pregnancies with known outcomes } \\
\text { does not indicate unexpected } \\
\text { effects on pregnancy outcome. The } \\
\text { available clinical experience is too } \\
\text { limited to exclude a risk } \\
\text { In a developmental toxicity study } \\
\text { in mice, no indication of maternal } \\
\text { toxicity, embryotoxicity, or } \\
\text { teratogenicity } \\
\text { Not recommended during } \\
\text { pregnancy }\end{array}$ & $\begin{array}{l}\text { No adequate data in } \\
\text { pregnant women } \\
\text { Animal studies } \\
\text { do not indicate } \\
\text { direct or indirect } \\
\text { harmful effects on } \\
\text { pregnancy, embryonic/ } \\
\text { fetal development, } \\
\text { parturition, or } \\
\text { postnatal development } \\
\text { As a precautionary } \\
\text { measure, it is } \\
\text { preferable to avoid the } \\
\text { use in pregnancy }\end{array}$ \\
\hline $\begin{array}{l}\text { Administration of live } \\
\text { vaccines to infants } \\
\text { exposed in utero }\end{array}$ & $\begin{array}{l}\text { Not recommended for } \\
5 \text { months following the mother's } \\
\text { last injection during pregnancy }\end{array}$ & $\begin{array}{l}\text { Generally not } \\
\text { recommended for } 16 \text { weeks } \\
\text { after the mother's last dose }\end{array}$ & $\begin{array}{l}\text { Not recommended for } 6 \text { months } \\
\text { following the mother's last infusion } \\
\text { during pregnancy }\end{array}$ & Not specified \\
\hline Effect on fertility & Preclinical data not available & $\begin{array}{l}\text { Preclinical and clinical data } \\
\text { not available }\end{array}$ & Insufficient preclinical data & $\begin{array}{l}\text { The effect has not } \\
\text { been evaluated }\end{array}$ \\
\hline
\end{tabular}

Note: Data from European Medicines Agency. ${ }^{83-86}$

Abbreviations: IgGI, immunoglobulin GI; TNF- $\alpha$, tumor necrosis factor- $\alpha$; IL, interlukin.

Reliable contraception should be introduced. The reason for these guidelines is a lack of controlled studies of biologics in pregnant women. ${ }^{9,32}$ Postmarketing experience with exposure to biologics in pregnancy is slowly accumulating, especially for drugs targeting tumor necrosis factor (TNF)- $\alpha$ in the setting of inflammatory bowel disease and inflammatory arthritis patients, with largely reassuring results. In the case of unplanned conception, most women, however, interrupt the biological therapy.

Despite some isolated reports of congenital malformations in children exposed to biologics during pregnancy, cumulative data from many hundreds of pregnancies have suggested that exposure to anti-TNF therapies at the time of conception or during the first trimester does not result in an increased risk of adverse pregnancy and fetal outcomes. ${ }^{74-76}$ Nevertheless, these apparently reassuring observations are based on a relatively small number of exposed pregnancies and should be interpreted with caution. In fact, no firm conclusions can be drawn about the safety of anti-TNF during pregnancy, and without further evidence, the use of these medications should be avoided at the time of conception. ${ }^{75,77}$ Observational studies in women with intestinal bowel disease treated with anti-TNF agents suggested that the disease itself (and not the treatment) can be regarded as the main reason for worse outcomes. ${ }^{78}$ Ustekinumab is a relatively new biologic drug, and experience during pregnancy is extremely limited..$^{79,80}$

There is a concern that the use of biologics during pregnancy could result in immunosuppression in a newborn and increased risk of infection, also taking into account the relatively long half-life of these drugs. ${ }^{74}$ Therefore, IgG antibodies should be discontinued as soon as pregnancy is recognized or in the case of difficult-to-control disease at least before gestational week 30 or preferably between weeks 20 and $22 .{ }^{72}$ One case of a fatal disseminated bacillus Calmette-Guérin infection after vaccination in an infant delivered to a mother with Crohn's disease treated throughout pregnancy with infliximab was reported ${ }^{81}$ The administration of live vaccines in a newborn that was exposed to biologic medication during the late second and third trimester should be postponed (Table 7).

As concerns male reproduction, no major adverse effects of TNF inhibitors have been discerned. ${ }^{72,82}$ The evidence regarding male fertility and anti-TNF therapies has even shown a beneficial effect, improving sperm count and function. ${ }^{60,67,80}$ No studies regarding the safety of ustekinumab in reproductive males exist. ${ }^{80}$ 


\section{Treatment of psoriasis in females in consideration of childbearing age}

Patient counseling before conception is important. A woman of reproductive age with psoriasis should be asked about her plans in order to select appropriate medications and provide exhaustive information. Adjustment of therapy in a patient planning to become pregnant or during early pregnancy is needed. ${ }^{9}$

In consideration of the available findings regarding the safety profile of psoriasis medications in pregnancy and the overall benign prognostic nature of psoriasis, the assessment of the risk/benefit ratio supports a cautious approach to women of childbearing age with psoriasis. In cases with severe disease, the best systemic drug to be used is CsA, based on the consistent amount of data suggesting reassuring aspects. These positive aspects and the absence of teratogenic and mutagenic potential permit a confident use of CsA in a female of childbearing age without a rigorous need of contraception, and with the possibility of a safe continuation of pregnancy after stopping the drug upon pregnancy recognition.

In clinical practice, the ordinary uncomplicated course of most psoriasis forms does not require the continuation of a systemic drug during pregnancy, which is usually stopped mainly for medico-legal issues. Literature suggests that CsA therapy during pregnancy should be carefully considered by the treating physician, but may be a safe alternative for patients with autoimmune disease refractory to conventional treatment. ${ }^{30}$

Also, cautious considerations should be done when prescribing a biologic therapy for psoriasis to a woman in reproductive years, taking into account her desire to conceive, as well as the elimination half-life and the persistence of detectable serum concentrations of the biological agent.

\section{Disclosure}

Gino A Vena has been a speaker, a consultant and/or an advisory board member for Abbvie, Astellas, Janssen-Cilag, Merck Serono, MSD, Novartis, Pfizer, and UCB. Nicoletta Cassano has been a speaker and/or a consultant for Abbvie, Astellas, Difa Cooper, Galderma, Merck Serono, Morgan Pharma, MSD, Novartis, Pfizer, Rottapharm Madaus, and UCB. Gilberto Bellia is an employee of Novartis Farma Italy. Delia Colombo is a part-time employee of Novartis Farma Italy and received grants from Allergan and Aventis.

\section{References}

1. Flatz L, Conrad C. Role of T-cell-mediated inflammation in psoriasis: pathogenesis and targeted therapy. Psoriasis Targets Ther. 2013;3: $1-10$.
2. Ceovic R, Mance M, Bukvic Mokos Z, Svetec M, Kostovic K, Stulhofer Buzina D. Psoriasis: female skin changes in various hormonal stages throughout life - puberty, pregnancy, and menopause. Biomed Res Int. 2013;2013:571912.

3. Colombo D, Cassano N, Bellia G, Vena GA. Gender medicine and psoriasis. World J Dermatol. 2014;3(3):36-44.

4. Østensen M, Villiger PM, Förger F. Interaction of pregnancy and autoimmune rheumatic disease. Autoimmun Rev. 2012;11(6-7):A437-A446.

5. Polese B, Gridelet V, Araklioti E, et al. The endocrine milieu and CD4 T-lymphocyte polarization during pregnancy. Front Endocrinol (Lausanne). 2014;5:106.

6. Raychaudhuri SP, Navare T, Gross J, Raychaudhuri SK. Clinical course of psoriasis during pregnancy. Int J Dermatol. 2003;42(7):518-520.

7. Murase JE, Chan KK, Garite TJ, Cooper DM, Weinstein GD. Hormonal effect on psoriasis in pregnancy and postpartum. Arch Dermatol. 2005;141(1):601-606.

8. Boyd AS, Morris LF, Phillips CM, Menter MA. Psoriasis and pregnancy: hormone and immune system interaction. Int J Dermatol. 1996;35(3):169-172.

9. Mervic L. Management of moderate to severe plaque psoriasis in pregnancy and lactation in the era of biologics. Acta Dermatovenerol Alp Pannonica Adriat. 2014;23(2):27-31.

10. Gudjonsson JE, Karason A, Runarsdottir EH, et al. Distinct clinical differences between HLA-Cw*0602 positive and negative psoriasis patients - an analysis of 1019 HLA-C and HLA-B-typed patients. $J$ Invest Dermatol. 2006;126(4):740-745.

11. Choon SE, Lai NM, Mohammad NA, Nanu NM, Tey KE, Chew SF. Clinical profile, morbidity, and outcome of adult-onset generalized pustular psoriasis: analysis of 102 cases seen in a tertiary hospital in Johor, Malaysia. Int J Dermatol. 2014;53(6):676-684.

12. Lotem M, Katzenelson V, Rotem A, Hod M, Sandbank M. Impetigo herpetiformis: a variant of pustular psoriasis or a separate entity? $J \mathrm{Am}$ Acad Dermatol. 1989;20(2 Pt 2):338-341.

13. Roth MM. Pregnancy dermatoses: diagnosis, management, and controversies. Am J Clin Dermatol. 2011;12(1):25-41.

14. Kondo RN, Araújo FM, Pereira AM, Lopes VC, Martins LM. Pustular psoriasis of pregnancy (impetigo herpetiformis) - case report. An Bras Dermatol. 2013;88(6 Suppl 1):186-189.

15. Patsatsi A, Theodoridis TD, Vavilis D, et al. Cyclosporine in the management of impetigo herpetiformis: a case report and review of the literature. Case Rep Dermatol. 2013;5(1):99-104.

16. Seeger JD, Lanza LL, West WA, Fernandez C, Rivero E. Pregnancy and pregnancy outcome among women with inflammatory skin diseases. Dermatology. 2007;214(1):32-39.

17. Harder E, Andersen AM, Kamper-Jørgensen M, Skov L. No increased risk of fetal death or prolonged time to pregnancy in women with psoriasis. J Invest Dermatol. 2014;134(6):1747-1749.

18. Ben-David G, Sheiner E, Hallak M, Levy A. Pregnancy outcome in women with psoriasis. J Reprod Med. 2008;53(3):183-187.

19. Cohen-Barak E, Nachum Z, Rozenman D, Ziv M. Pregnancy outcomes in women with moderate-to-severe psoriasis. J Eur Acad Dermatol Venereol. 2011;25(9):1041-1047.

20. Yang YW, Chen CS, Chen YH, Lin HC. Psoriasis and pregnancy outcomes: a nationwide population-based study. J Am Acad Dermatol. 2011;64(1):71-77.

21. Lima XT, Janakiraman V, Hughes MD, Kimball AB. The impact of psoriasis on pregnancy outcomes. J Invest Dermatol. 2012;132(1):85-91.

22. Marik PE. Hypertensive disorders of pregnancy. Postgrad Med. 2009;121(2):69-76.

23. Bandoli G, Johnson DL, Jones KL, et al. Potentially modifiable risk factors for adverse pregnancy outcomes in women with psoriasis. $\mathrm{BrJ}$ Dermatol. 2010;163:334-339.

24. Bush MC, Patel S, Lapinski RH, Stone JL. Perinatal outcomes in inflammatory bowel disease. J Matern Fetal Neonatal Med. 2004;15(4):237-241.

25. Lin HC, Chen SF, Lin HC, Chen YH. Increased risk of adverse pregnancy outcomes in women with rheumatoid arthritis: a nationwide populationbased study. Ann Rheum Dis. 2010;69(4):715-717. 
26. Ruiz V, Manubens E, Puig L. Psoriasis in pregnancy: a review (I). Actas Dermosifiliogr. 2014;105(8):734-743.

27. Horn EJ, Chambers CD, Menter A, Kimball AB; International Psoriasis Council. Pregnancy outcomes in psoriasis: why do we know so little? J Am Acad Dermatol. 2009;61(2):e5-e8.

28. Ramoz LL, Patel-Shori NM. Recent changes in pregnancy and lactation labeling: retirement of risk categories. Pharmacotherapy. 2014;34(4): 389-395.

29. Lam J, Polifka JE, Dohil MA. Safety of dermatologic drugs used in pregnant patients with psoriasis and other inflammatory skin diseases. J Am Acad Dermatol. 2008;59(2):295-315.

30. Paziana K, Del Monaco M, Cardonick E, et al. Ciclosporin use during pregnancy. Drug Saf. 2013;36(5):279-294.

31. Lin HC, Hunnicutt JN, Moustafa FA, et al. Pharmacological treatments in pregnant women with psoriasis in the USA. Br J Dermatol. 2015;172(3):807-810.

32. Bae YS, Van Voorhees AS, Hsu S, et al. Review of treatment options for psoriasis in pregnant or lactating women: from the Medical Board of the National Psoriasis Foundation. J Am Acad Dermatol. 2012;67(3):459-477.

33. Marciniak B, Patro-Małysza J, Poniedziałek-Czajkowska E, KimberTrojnar Z, Leszczyńska-Gorzelak B, Oleszczuk J. Glucocorticoids in pregnancy. Curr Pharm Biotechnol. 2011;12(5):750-757.

34. Chi CC, Lee CW, Wojnarowska F, Kirtschig G. Safety of topical corticosteroids in pregnancy. Cochrane Database Syst Rev. 2009;(3):CD007346.

35. Chi CC, Mayon-White RT, Wojnarowska FT. Safety of topical corticosteroids in pregnancy: a population-based cohort study. $J$ Invest Dermatol. 2011;131(4):884-891.

36. Hviid A, Mølgaard-Nielsen D. Corticosteroid use during pregnancy and risk of orofacial clefts. CMAJ. 2011;183(7):796-804.

37. Chi CC, Wang SH, Mayon-White R, Wojnarowska F. Pregnancy outcomes after maternal exposure to topical corticosteroids: a UK population-based cohort study. JAMA Dermatol. 2013;149(11): 1274-1280.

38. Skuladottir H, Wilcox A, McConnaughey R, Vindenes H, Lie RT. Firsttrimester nonsystemic corticosteroid use and the risk of oral clefts in Norway. Ann Epidemiol. 2014;24(9):635-640.

39. Chi CC, Kirtschig G, Aberer W, et al. Evidence-based (S3) guideline on topical corticosteroids in pregnancy. Br J Dermatol. 2011;165(5): 943-952.

40. Tyler KH, Zirwas MJ. Pregnancy and dermatologic therapy. JAm Acad Dermatol. 2013;68(4):663-671.

41. Murase JE, Heller MM, Butler DC. Safety of dermatologic medications in pregnancy and lactation: Part I. Pregnancy. J Am Acad Dermatol. 2014;70(3):401. e1-e14.

42. Wheeler LA, Saperstein MD, Lowe NJ. Mutagenicity of urine from psoriatic patients undergoing treatment with coal tar and ultraviolet light. J Invest Dermatol. 1981;77(2):181-185.

43. Khan A, Bourgeois J, Mohide P. Agnathia-otocephaly complex in a fetus with maternal use of topical 1\% salicylate. Clin Dysmorphol. 2008; 17(1):75-76.

44. Nakhai-Pour HR, Bérard A. Major malformations after first trimester exposure to aspirin and NSAIDs. Expert Rev Clin Pharmacol. 2008;1(5):605-616.

45. Menter A. Pharmacokinetics and safety of tazarotene. J Am Acad Dermatol. 2000;43(2 Pt 3):S31-S35.

46. Franssen ME, van der Wilt GJ, de Jong PC, Bos RP, Arnold WP. A retrospective study of the teratogenicity of dermatological coal tar products. Acta Derm Venereol. 1999;79(5):390-391.

47. Tang-Liu DD, Matsumoto RM, Usansky JI. Clinical pharmacokinetics and drug metabolism of tazarotene: a novel topical treatment of acne and psoriasis. Clin Pharmacokinet. 1999;37(4):273-287.

48. El-Saie LT, Rabie AR, Kamel MI, Seddeik AK, Elsaie ML. Effect of narrowband ultraviolet B phototherapy on serum folic acid levels in patients with psoriasis. Lasers Med Sci. 2011;26(4):481-485.
49. Rose RF, Batchelor RJ, Turner D, Goulden V. Narrowband ultraviolet B phototherapy does not influence serum and red cell folate levels in patients with psoriasis. J Am Acad Dermatol. 2009;61(2):259-262.

50. Stern RS, Lange R. Outcomes of pregnancies among women and partners of men with a history of exposure to methoxsalenphotochemotherapy (PUVA) for the treatment of psoriasis. Arch Dermatol. 1991;127(3):347-350.

51. Gunnarskog JG, Källén AJ, Lindelöf BG, Sigurgeirsson B. Psoralen photochemotherapy (PUVA) and pregnancy. Arch Dermatol. 1993; 129(3):320-323.

52. Park-Wyllie L, Mazzotta P, Pastuszak A, et al. Birth defects after maternal exposure to corticosteroids: prospective cohort study and meta-analysis of epidemiological studies. Teratology. 2000;62(6):385-392.

53. Bay Bjørn AM, Ehrenstein V, Hundborg HH, Nohr EA, Sørensen HT, Nørgaard M. Use of corticosteroids in early pregnancy is not associated with risk of oral clefts and other congenital malformations in offspring. Am J Ther. 2014;21(2):73-80.

54. Skuladottir H, Wilcox AJ, Ma C, et al. Corticosteroid use and risk of orofacial clefts. Birth Defects Res A Clin Mol Teratol. 2014;100(6): 499-506.

55. Lamarque V, Leleu MF, Monka C, Krupp P. Analysis of 629 pregnancy outcomes in renal transplant recipients with Sandimmune. Transplant Proc. 1997;29(5):2480.

56. Bar Oz B, Hackman R, Einarson T, Koren G. Pregnancy outcome after cyclosporine therapy during pregnancy: a meta-analysis. Transplantation. 2001;71(8):1051-1055.

57. Armenti VT, McGrory CH, Cater JR, Radomski JS, Moritz MJ. Pregnancy outcomes in female transplant recipients. Transplant Proc. 1998;30(5):1732-1734.

58. Hale EK, Pomeranz MK. Dermatologic agents during pregnancy and lactation: an update and clinical review. Int J Dermatol. 2002;41(4): 197-203.

59. Altomare G, Ayala F, Bardazzi F, et al. Consensus on the use of cyclosporine in dermatological practice. G Ital Dermatol Venereol. 2014;149(5):607-625.

60. Millsop JW, Heller MM, Eliason MJ, Murase JE. Dermatological medication effects on male fertility. Dermatol Ther. 2013;26(4): 337-346.

61. Larsen FG, Jakobsen P, Knudsen J, et al. Conversion of acitretin to etretinate in psoriatic patients is influenced by ethanol. $J$ Invest Dermatol. 1993;100(5):623-627.

62. Vena GA, Cassano N. The effects of alcohol on the metabolism and toxicology of anti-psoriasis drugs. Expert Opin Drug Metab Toxicol. 2012;8(8):959-972.

63. Lloyd ME, Carr M, McElhatton P, Hall GM, Hughes RA. The effects of methotrexate on pregnancy, fertility and lactation. QJM. 1999;92(10): 551-563.

64. Hyoun SC, Obican SG, Scialli AR. Teratogen update: methotrexate. Birth Defects Res A Clin Mol Teratol. 2012;94(4):187-207.

65. Lewden B, Vial T, Elefant E, et al. Low dose methotrexate in the first trimester of pregnancy: results of a French collaborative study. J Rheumatol. 2004;31(12):2360-2365.

66. Martín MC, Barbero P, Groisman B, Aguirre MÁ, Koren G. Methotrexate embryopathy after exposure to low weekly doses in early pregnancy. Reprod Toxicol. 2014;43:26-29.

67. Grunewald S, Paasch U, Glander HJ. Systemic dermatological treatment with relevance for male fertility. $J$ Dtsch Dermatol Ges. 2007;5(1):15-21.

68. Geiger JM, Baudin M, Saurat JH. Teratogenic risk with etretinate and acitretin treatment. Dermatology. 1994;189:109-116.

69. Geiger JM, Walker M. Is there a reproductive safety risk in male patients treated with acitretin (neotigason/soriatane)? Dermatology. 2002;205(2):105-107.

70. Han JY, Choi JS, Chun JM, et al. Pregnancy outcome of women transfused during pregnancy with blood products inadvertently obtained from donors treated with acitretin. J Obstet Gynaecol. 2009;29(8):694-697. 
71. Kane SV, Acquah LA. Placental transport of immunoglobulins: a clinical review for gastroenterologists who prescribe therapeutic monoclonal antibodies to women during conception and pregnancy. Am J Gastroenterol. 2009;104(1):228-233.

72. Østensen M, Förger F. How safe are anti-rheumatic drugs during pregnancy? Curr Opin Pharmacol. 2013;13(3):470-475.

73. Martin PL, Sachs C, Imai N, et al. Development in the cynomolgus macaque following administration of ustekinumab, a human anti-IL12/23p40 monoclonal antibody, during pregnancy and lactation. Birth Defects Res B Dev Reprod Toxicol. 2010;89(5):351-363.

74. Chambers CD, Johnson DL. Emerging data on the use of antitumor necrosis factor-alpha medications in pregnancy. Birth Defects Res A Clin Mol Teratol. 2012;94(8):607-611.

75. Marchioni RM, Lichtenstein GR. Tumor necrosis factor-alpha inhibitor therapy and fetal risk: a systematic literature review. World $J$ Gastroenterol. 2013;19(17):2591-2602.

76. Hyrich KL, Verstappen SM. Biologic therapies and pregnancy: the story so far. Rheumatology (Oxford). 2014;53(8):1377-1385.

77. Verstappen SM, King Y, Watson KD, et al. Anti-TNF therapies and pregnancy: outcome of 130 pregnancies in the British Society for Rheumatology Biologics Register. Ann Rheum Dis. 2011;70(5): 823-826.

78. Yarur A, Kane SV. Update on pregnancy and breastfeeding in the era of biologics. Dig Liver Dis. 2013;45(10):787-794.

79. Sheeran C, Nicolopoulos J. Pregnancy outcomes of two patients exposed to ustekinumab in the first trimester. Australas J Dermatol. 2014;55(3): 235-236.
80. Yiu ZZ, Griffiths CE, Warren RB. Safety of biological therapies for psoriasis: effects on reproductive potential and outcomes in male and female patients. Br J Dermatol. 2014;171(3):485-491.

81. Cheent K, Nolan J, Shariq S, Kiho L, Pal A, Arnold J. Case report: fatal case of disseminated BCG infection in an infant born to a mother taking infliximab for Crohn's disease. J Crohns Colitis. 2010;4(5):603-605.

82. Puchner R, Danninger K, Puchner A, Pieringer H. Impact of TNFblocking agents on male sperm characteristics and pregnancy outcomes in fathers exposed to TNF-blocking agents at time of conception. Clin Exp Rheumatol. 2012; 30(5):765-767.

83. Summary of product characteristics. European Medicines Agency; 2010. Available from: http://www.ema.europa.eu/docs/en_GB/document_ library/EPAR_-_Product_Information/human/000262/WC500027361. pdf. Accessed January 6, 2015.

84. Summary of product characteristics. European Medicines Agency; 2010. Available from: http://www.ema.europa.eu/docs/en_GB/document_ library/EPAR_-_Product_Information/human/000958/WC500058513. pdf. Accessed January 6, 2015.

85. Summary of product characteristics. European Medicines Agency; 2010. Available from: http://www.ema.europa.eu/docs/en_GB/document library/EPAR_-_Product_Information/human/000240/WC500050888. pdf. Accessed January 6, 2015.

86. Summary of product characteristics. European Medicines Agency; 2010 Available from: http://www.ema.europa.eu/docs/en_GB/document_ library/EPAR_-_Product_Information/human/000481/WC500050870. pdf. Accessed January 6, 2015.
Psoriasis: Targets and Therapy

\section{Publish your work in this journal}

Psoriasis: Targets and Therapy is international, peer-reviewed, open access journal focusing on psoriasis, nail psoriasis, psoriatic arthritis and related conditions, identification of therapeutic targets and the optimal use of integrated treatment interventions to achieve improved outcomes and quality of life. The manuscript management system

\section{Dovepress}

is completely online and includes a very quick and fair peer-review system. Visit http://www.dovepress.com/testimonials.php to read real quotes from published authors. 